\title{
Resistant dextrin, as a prebiotic, improves insulin resistance and inflammation in women with type 2 diabetes: a randomised controlled clinical trial
}

\author{
Akbar Aliasgharzadeh ${ }^{1}$, Parvin Dehghan ${ }^{2 *}$, Bahram Pourghassem Gargari $^{3}$ and \\ Mohammad Asghari-Jafarabadi ${ }^{4}$ \\ ${ }^{1}$ Faculty of Medicine, Bone Research Center, Tabriz University of Medical Sciences, Tabriz, Iran \\ ${ }^{2}$ Faculty of Nutrition, Nutrition Research Center, Student Research Committee, Tabriz University of Medical Sciences, \\ Tabriz, Iran \\ ${ }^{3}$ Faculty of Nutrition, Tabriz University of Medical Sciences, Tabriz, Iran \\ ${ }^{4}$ Medical Education Research Center, Faculty of Health, Tabriz University of Medical Sciences, Tabriz, Iran \\ (Submitted 3 June 2014 - Final revision received 16 September 2014 - Accepted 15 October 2014)
}

\section{Abstract}

Improvement of insulin resistance and inflammation is a basic strategy in the management of type 2 diabetes. There is limited evidence that prebiotics improve insulin resistance and inflammation. However, the ameliorating effect of resistant dextrin, as a prebiotic, on insulin resistance and inflammation in patients with type 2 diabetes has not been investigated so far. Therefore, the present study aimed to examine the effects of resistant dextrin on insulin resistance and inflammation in type 2 diabetic patients. In a randomised controlled clinical trial, fifty-five women with type 2 diabetes were assigned to two groups: the intervention group ( $n$ 30) and the control group ( $n$ 25). The intervention group received a daily supplement of $10 \mathrm{~g}$ resistant dextrin and the control group received a similar amount of maltodextrin as placebo for 8 weeks. Fasting plasma glucose (FPG), HbA1c, insulin, high-sensitivity C-reactive protein (hs-CRP), IL-6, TNF- $\alpha$, malondialdehyde (MDA) and serum endotoxin concentrations were measured before and after the intervention. Data were analysed using SPSS (version 13). Paired and unpaired $t$ tests and ANCOVA were used to compare quantitative variables after the intervention. Patients supplemented with resistant dextrin exhibited a significant decrease in fasting insulin $(20 \cdot 1$ pmol/1, 22.8\%), homeostasis model assessment of insulin resistance $(1 \cdot 3,24 \cdot 9 \%)$, quantitative insulin sensitivity check index $(0 \cdot 2,7 \cdot 2 \%)$, IL-6 (1.4 pg/ml, $28 \cdot 4 \%)$, TNF- $\alpha$ $(5.4 \mathrm{pg} / \mathrm{ml}, 18 \cdot 8 \%)$, MDA $(1.2 \mathrm{nmol} / \mathrm{ml}, 25.6 \%)$ and endotoxin $(6 \cdot 2$ endotoxin units $/ \mathrm{ml}, 17.8 \%)$ concentrations than those supplemented with maltodextrin $(P<0.05)$. Decreases in FPG $(0.05 \mathrm{mmol} / 1,0.6 \%)$, HbA1c $(0.5 \%, 9.6 \%)$ and hs-CRP $(2.7 \mathrm{ng} / \mathrm{ml}, 35.1 \%) \mathrm{concentrations}$ in the resistant dextrin group were not significant when compared with the maltodextrin group. In conclusion, resistant dextrin supplementation can modulate inflammation and improve insulin resistance in women with type 2 diabetes.

\section{Key words: Resistant dextrin: Insulin resistance: Cytokines: Type 2 diabetes}

Diabetes mellitus is a widespread metabolic disease in developing and developed countries. In Iran, the prevalence rate of known diabetes and impaired fasting glucose has been reported to be 16.3 and $11.9 \%$, respectively. The prevalence of diabetes has been found to be higher in women $(25.3 \%)$ than in men $(9 \cdot 2 \%)^{(1)}$. This disease is characterised by the presence of hyperglycaemia together with insulin resistance, oxidative stress as well as elevated production of cytokines, such as C-reactive protein, IL- 6 and TNF- $\alpha^{(2)}$. In recent years, it has been documented that a change in the composition of gut microflora towards Gram-negative bacteria, particularly an elevated Firmicutes:Bacteroidetes ratio, plays an important role in the cascade of inflammation and in the development of systemic insulin resistance and other metabolic disorders in type 2 diabetic patients ${ }^{(3)}$. Lipopolysaccharide is a major component of the outer cell membrane in Gram-negative bacteria, and it is known to be an initiator of metabolic impairments such as chronic low-grade inflammation and insulin resistance in obese subjects and onset of type 2 diabetes ${ }^{(3)}$. Recently, prebiotics such as resistant dextrin have been proposed as a new therapeutic approach in the management of type 2 diabetes and its complications ${ }^{(4)}$. NUTRIOSE ${ }^{\circledR} 06$ is a

Abbreviations: FPG, fasting plasma glucose; GLP, glucagon-like peptide; HOMA-IR, homeostasis model assessment of insulin resistance; hs-CRP, high-sensitivity C-reactive protein; IRS, insulin receptor substrate; MDA, malondialdehyde; QUICKI, quantitative insulin sensitivity check index. 
purified resistant dextrin, a glucose polymer (rich in $\alpha-1,4$ and $\alpha-1,6$ linkages) derived from wheat (NUTRIOSE ${ }^{\circledR} \mathrm{FB} 06$ ) or maize (NUTRIOSE ${ }^{\circledR}$ FM06). NUTRIOSE ${ }^{\circledR} 06$ is incompletely hydrolysed and absorbed in the small intestine. About $15 \%$ of this resistant dextrin is digested in the small intestine while $75 \%$ is fermented in the colon and about $10 \%$ of it is excreted in the faeces ${ }^{(5)}$. Its available energy value ranges from $7 \cdot 1$ to $8 \cdot 4 \mathrm{~kJ} / \mathrm{g}(1 \cdot 7$ to $2 \cdot 0 \mathrm{kcal} / \mathrm{g})$. NUTRIOSE ${ }^{\circledR} 06$ is well tolerated by the human digestive system up to a dose of $45 \mathrm{~g} / \mathrm{d}^{(5)}$. It has been shown that NUTRIOSE ${ }^{\circledR} 06$ can induce metabolic and health benefits via selective modulation of the human gut microflora towards Lactobacillus spp., and bacteroides and butyrogenic genera such as Clostridium cluster XIVa and Roseburia genus ${ }^{(6)}$. There is limited evidence on the effects of resistant dextrin on glycaemic status and inflammation. Some animal studies have reported the beneficial effects of resistant dextrin on inflammation ${ }^{(7)}$ and glycaemic status ${ }^{(8)}$. For example, NUTRIOSE ${ }^{\circledR} 06$ has been shown to reduce postprandial glycaemic kinetics in dogs ${ }^{(8)}$, whereas it has been shown to increase the number of intestinal butyrogenic bacterial strains and decrease inflammatory disorders in colitis piglets ${ }^{(9)}$. Some human studies have evaluated the effects of NUTRIOSE ${ }^{\circledR} 06$ on glycaemic status and insulin resistance ${ }^{(9)}$, energy intake, and body weight ${ }^{(10)}$. To the best of our knowledge, no study has evaluated the effects of resistant dextrin on inflammatory biomarkers in human subjects. The review of the literature related to this area has shown a need for further research on the health effects of NUTRIOSE ${ }^{\circledR} 06$ especially on humans. Therefore, the present study tests the hypothesis that NUTRIOSE ${ }^{\circledR} 06$, as a resistant dextrin, can modulate insulin resistance, inflammation and metabolic endotoxaemia in women with type 2 diabetes.

\section{Materials and methods}

\section{Patients}

Female patients ( $n$ 75; aged 30-65 years) from the Iran Diabetes Society and Endocrinology and Metabolism Clinics at Tabriz University of Medical Sciences voluntarily participated in the present triple-blind randomised controlled study conducted from December 2011 to February 2012. Patients were included if they had type 2 diabetes for more than 6 months, used anti-diabetic drugs and maintained on them during the study period, and had a normal diet and BMI $>25 \mathrm{~kg} / \mathrm{m}^{2}$ in the last 3 months. Type 2 diabetes was defined as a fasting plasma glucose (FPG) level $\geq 7 \mathrm{mmol} / \mathrm{l}$ $(\geq 126 \mathrm{mg} / \mathrm{dl})^{(11)}$. Patients were excluded if they had a history of gastrointestinal, CVD, renal, thyroid, liver or pancreatic diseases; were pregnant, smokers or lactating; were consuming pre/probiotic products, antibiotics, antacids, alcohol, antidiarrhoeal, anti-inflammatory and lipid-lowering drugs, laxatives, or insulin; and, finally, had a typical fibre intake of $>30 \mathrm{~g}$. At the beginning of the trial, data including age, medication history and diabetes duration were collected using a questionnaire. The trial was conducted according to the guidelines laid down in the Declaration of Helsinki, and all procedures involving human subjects were approved by the Ethics Committee of Tabriz University of Medical Sciences and were registered on the Iranian Registry of Clinical Trials website (http://www.irct.ir/; IRCT201 110293253N4). Written informed consent was obtained from each patient.

\section{Experimental design}

Patients were randomly divided into two groups: the intervention group ( $n$ 30) and the control group ( $n$ 25). Randomisation was based on the block randomisation procedure with a block size of 4 . To match the groups, patients with the same categories of BMI and age were allocated to each block. The allocation sequence was generated randomly by using random allocation software. This software enables investigation to control different attributes of the random allocation sequence and produces qualified lists for parallel-group trials $^{(12)}$. The intervention group received a supplement of $10 \mathrm{~g} / \mathrm{d}$ of resistant dextrin (NUTRIOSE ${ }^{\circledR} 06 \mathrm{FM}$; Roquette) and the control group received a similar amount of maltodextrin as placebo (Jiujiang Huirong Trade Company Limited) for 8 weeks. Both NUTRIOSE ${ }^{\circledR} 06$ and maltodextrin were powdered and given to the patients in similar opaque packages. The supplements were divided into two packages of $5 \mathrm{~g}$ each to be taken during breakfast and dinner with a cup of water. These supplements were divided between patients in accordance with the allocation codes after randomisation. The patients received half of the packages at the beginning of the trial and the remaining packages in the middle of the trial. To maintain blinding, allocation was performed by an investigator with no clinical involvement in the study, and the investigators as well as the statistician remained blind until the end of the analysis. The supplements were distributed among the patients in accordance with the allocation codes after randomisation. To minimise the patients' withdrawal and to ensure their consumption of supplements, they received a phone call every week. Throughout the trial, the patients were asked to have their usual physical activity and diet. All the collected data were coded for analysis.

The sample size was determined based on the primary outcome of changes in TNF- $\alpha$ level, which was obtained from a pilot study on five patients. A minimum sample size of twenty-two was determined for each group according to Pocock's formula ${ }^{(13)}$, with a $95 \%$ CI and a power of $0 \cdot 80$. To account for an anticipated dropout of $25 \%$, the sample size was increased to twenty-seven in each group. The primary outcomes of the study were FPG, HbA1c, fasting insulin, homeostasis model assessment of insulin resistance (HOMA-IR), quantitative insulin sensitivity check index (QUICKI), high-sensitivity C-reactive protein (hs-CRP), TNF- $\alpha$, IL-6, malondialdehyde (MDA) and endotoxin, while the secondary outcomes were changes in body weight and energy intake. Changes in energy intake and body weight for glycaemic parameters, MDA and inflammatory biomarkers were considered as covariates in the present study. 


\section{Body-weight and dietary intake assessment}

Anthropometric indices including body weight and height were measured at baseline and at the end of the trial. BMI was calculated as weight (in $\mathrm{kg}$ ) divided by squared height (in $\mathrm{m}^{2}$ ). Dietary intakes were evaluated using a $3 \mathrm{~d}$ food diary ( 2 weekdays and 1 weekend) at baseline and at the end of the trial. Dietary intakes were analysed using Nutritionist 4 software (First Databank, Inc., Hearst Corporation) using the database from tables of content and nutritional value of Iranian food products.

\section{Biochemical measurements}

At baseline and at the end of the trial, after an overnight fast, $10 \mathrm{ml}$ of venous blood samples were collected and transferred into two Vacutainer tubes (Wuhan Desheng Chemical Technology Co., Ltd.), one of which contained EDTA for the measurement of HbA1c and the other was used for the measurements of FPG, insulin, MDA, inflammatory biomarkers including hs-CRP, TNF- $\alpha$, IL- 6 and serum endotoxin concentrations. The serum samples were separated from whole blood by centrifugation at $2500 \mathrm{rpm}$ for $10 \mathrm{~min}$ (Beckman Avanti J-25; Beckman Coulter) at room temperature. Glycaemic indices were analysed on the day of sampling and the remaining serum was stored at $-70^{\circ} \mathrm{C}$ until assay time. FPG concentration was measured by an enzymatic method using an Abbott Model Alcyon 300, USA autoanalyser with a kit from Pars Azmoon Company. Serum insulin concentration was measured by a chemiluminescent immunoassay method (LIAISON Analyser 310360; Diasorin S.P.A.). HOMA-IR ${ }^{(14)}$ and QUICKI ${ }^{(15)}$ were calculated according to the following formulae:

$$
\begin{aligned}
\text { HOMA-IR }=(\text { fasting insulin }(\mathrm{mU} / \mathrm{ml}) \times \mathrm{FPG}(\mathrm{mmol} / \mathrm{l})) / 22 \cdot 5, \\
\text { QUICKI }=\underset{\text { insulin }(\mu \mathrm{U} / \mathrm{ml})) .}{1 /(\log \mathrm{FBG}(\mathrm{mmol} / \mathrm{l})+\log \text { fasting plasma }}
\end{aligned}
$$

HbA1c level was determined in whole blood using an automated HPLC analyser with commercially available kits (Bio-Rad D-10; Bio-Rad Laboratories).

Serum hs-CRP concentration was determined using an immunoturbidimetric assay (Pars Azmoon Company). IL-6 and TNF- $\alpha$ levels were measured with an ELISA kit (eBioscience). The level of serum MDA, a thiobarbituric acid-reactive substance, was measured by the reaction with thiobarbituric acid to produce a pink-coloured complex. Its fluorescence intensity was measured at $547 \mathrm{~nm}$ with excitation at $525 \mathrm{~nm}$ by a spectrofluorimeter (model SFM 25A; Kontron) ${ }^{(16)}$. Serum endotoxin concentration was measured by a limulus amoebocyte lysate assay kit (LAL kit endpointQCL1000; Cambrex BioScience). Its fluorescence intensity was measured at $547 \mathrm{~nm}$.

\section{Statistical analyses}

Data were analysed using SPSS software (version 13; SPSS Inc.). All statistical analyses were performed based on an intention-to-treat analysis. Results are presented as means and standard deviations. The normality of data distribution was evaluated by the one-sample Kolmogorov-Smirnov test. The following analyses were performed for both primary and secondary outcomes. Unpaired $t$ tests (for baseline measurements) and ANCOVA were used to compare quantitative variables after the intervention. Quantitative data, collected at the beginning and end of the trial, were compared by the paired $t$ test. hs-CRP analyses were performed after log transformation. The effects of medications used in the two groups were compared by the Mann-Whitney $U$ test. ANCOVA adjusting for baseline measurements of the primary outcome and covariates (including changes in energy intake and body weight) was used to identify any differences between the two groups after the intervention. For calculating the percentage of mean changes in the biomarkers, at the beginning and end of the trial, mean changes in the biomarkers from baseline in each group were calculated by the following formula:

((8-week values - baseline values $) /$ baseline values $) \times 100$.

Mean changes in the biomarkers between the groups were calculated as follows:

$(($ Intervention values - control values $) /$ control values $) \times 100$.

$P<0.05$ were considered as statistically significant.

\section{Results}

Of a total of seventy-five patients, fifty-five completed the trial (intervention group $n 30$ and control group $n$ 25; Fig. 1). The patients did not report any adverse effects or symptoms with respect to resistant dextrin supplementation. Table 1 presents the baseline characteristics of the patients in the two groups. The initial characteristics were similar at baseline in both groups.

\section{Effects of resistant dextrin supplementation on body weight and dietary intakes}

At baseline, no significant differences were observed between the two groups in relation to body weight and BMI (Table 1). After 8 weeks of supplementation, body weight and BMI did not change significantly in the maltodextrin group, but decreased significantly in the resistant dextrin group (Table 2). These changes were found to be significant in the resistant dextrin group compared with those at baseline $(P<0 \cdot 05$; paired Student's $t$ test $)$.

Dietary intakes of macronutrients are given in Table 2 . There were no significant differences in the intakes of energy and macronutrients between the two groups at baseline. Intakes of energy, carbohydrate and total fat were found to be significantly different between the two groups at the end of the trial $(P<0.05$; ANCOVA adjusted for baseline values). Intakes of energy and total fat decreased significantly in the resistant dextrin group compared with those at baseline $(P<0 \cdot 05$; paired Student's $t$ test $)$, but did not differ significantly in the maltodextrin group. 


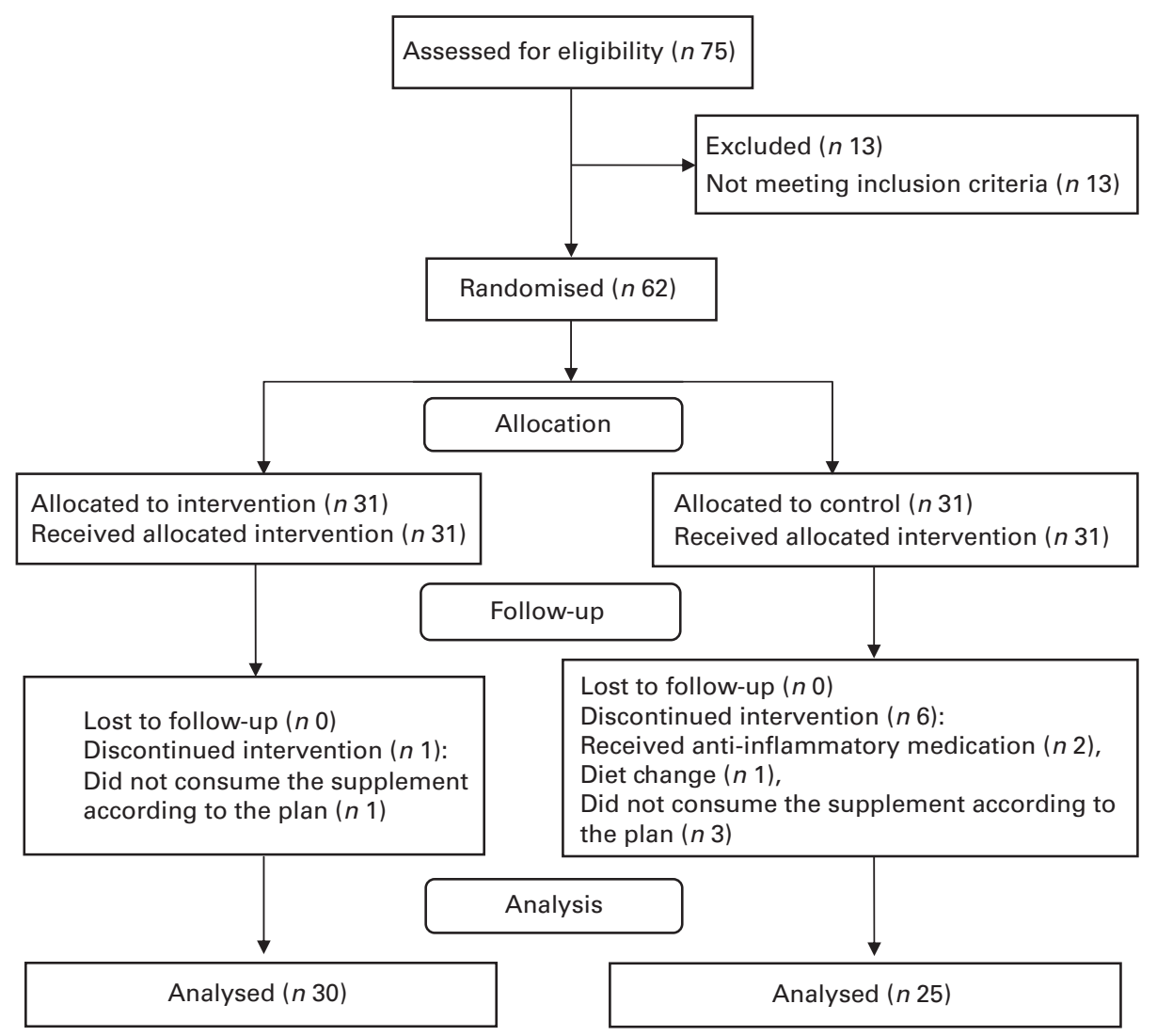

Fig. 1. Flow chart of the study design.

Effects of resistant dextrin supplementation on glycaemic indices, inflammatory parameters and malondialdehyde

At baseline, no significant differences in glycaemic status between the resistant dextrin and maltodextrin groups were observed (Table 3). However, at the end of the trial, there was a significant decrease in fasting insulin concentration $(20 \cdot 1 \mathrm{pmol} / /$ 1, 22.8\%), HOMA-IR (1.3, 24.9\%) and QUICKI $(0 \cdot 2,7 \cdot 2 \%)$ in the resistant dextrin group compared with the maltodextrin group $(P<0.05$; ANCOVA adjusted for energy intake, weight changes and baseline values). The reduction in FPG $(0.05 \mathrm{mmol} / \mathrm{l}$, $0.6 \%)$ and HbA1c $(0.5 \%, 9.6 \%)$ levels was not significant in the resistant dextrin group compared with the maltodextrin group ( $P>0.05$; ANCOVA adjusted for energy intake, weight changes and baseline values). The two groups did not show any significant difference in baseline inflammatory biomarkers, i.e. MDA and endotoxin (Table 4). After 8 weeks of supplementation, significant decreases in the levels of IL-6 (1.4 pg/ml, 28.4\%), TNF- $\alpha(5.4 \mathrm{pg} / \mathrm{ml}, 18.8 \%)$, MDA $(1.2 \mathrm{nmol} / \mathrm{ml}, 25.6 \%)$ and endotoxin $(6 \cdot 2$ endotoxin units $/ \mathrm{ml}, 17 \cdot 8 \%)$ were observed in the resistant dextrin group compared with the maltodextrin group ( $P<0.05$; ANCOVA adjusted for energy intake, weight changes and baseline values). The reduction in the levels of hs-CRP ( $2 \cdot 7 \mathrm{ng} / \mathrm{ml}, 35 \cdot 1 \% ; P>0 \cdot 05)$ was not significant.

\section{Discussion}

It has been hypothesised that prebiotics can modulate metabolic disorders such as blood glucose homeostasis, oxidative stress and inflammation by reducing metabolic endotoxaemia $^{(17,18)}$. The results of the present study demonstrated that supplementation with resistant dextrin for 8 weeks significantly decreased the levels of body weight, BMI, fasting insulin, HOMA-IR, QUICKI, IL-6, TNF- $\alpha$, MDA and endotoxin in the intervention group compared with the control group. However, reductions in the levels of FPG, HbA1c and hs-CRP were not significant.

Table 1. Baseline characteristics of the study patients

(Mean values and standard deviations or ranges; number of participants and percentages)

\begin{tabular}{|c|c|c|c|c|}
\hline \multirow[b]{2}{*}{ Variables } & \multicolumn{2}{|c|}{$\begin{array}{l}\text { Maltodextrin } \\
\text { group ( } n 25)\end{array}$} & \multicolumn{2}{|c|}{$\begin{array}{l}\text { Resistant dex- } \\
\text { trin group }(n 30)\end{array}$} \\
\hline & Mean & SD & Mean & SD \\
\hline Age (years) & $49 \cdot 6$ & 8.4 & $49 \cdot 2$ & 9.60 \\
\hline Range & \multicolumn{2}{|c|}{$34-60$} & \multicolumn{2}{|c|}{$33-65$} \\
\hline \multicolumn{5}{|l|}{ Menopausal status } \\
\hline \multicolumn{5}{|l|}{ Pre-menopausal } \\
\hline$n$ & \multicolumn{2}{|c|}{9} & \multicolumn{2}{|c|}{9} \\
\hline$\%$ & \multicolumn{2}{|c|}{36} & \multicolumn{2}{|c|}{30} \\
\hline \multicolumn{5}{|l|}{ Postmenopausal } \\
\hline$n$ & \multicolumn{2}{|c|}{16} & \multicolumn{2}{|c|}{21} \\
\hline$\%$ & \multicolumn{2}{|c|}{64} & \multicolumn{2}{|c|}{70} \\
\hline Weight (kg) & 71.8 & 3.5 & $76 \cdot 0$ & 11.5 \\
\hline Height $(\mathrm{cm})$ & $152 \cdot 6$ & 6.4 & $154 \cdot 7$ & 6.5 \\
\hline $\mathrm{BMI}\left(\mathrm{kg} / \mathrm{m}^{2}\right)$ & 30.8 & $5 \cdot 2$ & 31.8 & 4.5 \\
\hline Diabetes duration (years) & $5 \cdot 2$ & 4.4 & 6.9 & $5 \cdot 2$ \\
\hline Metformin, $500 \mathrm{mg}$ (tablets/d) & $2 \cdot 6$ & 1.1 & $3 \cdot 1$ & 0.9 \\
\hline Glibenclamide, $5 \mathrm{mg}$ (tablets $/ \mathrm{d}$ ) & 1.7 & 1.2 & $2 \cdot 1$ & 1.3 \\
\hline
\end{tabular}


Table 2. Anthropometric indices and dietary intakes of the study patients at baseline and at the end of the trial

(Mean values and standard deviations)

\begin{tabular}{|c|c|c|c|c|c|}
\hline \multirow[b]{2}{*}{ Variables } & \multirow[b]{2}{*}{ Period } & \multicolumn{2}{|c|}{$\begin{array}{l}\text { Maltodextrin group } \\
\qquad(n 25)\end{array}$} & \multicolumn{2}{|c|}{$\begin{array}{l}\text { Resistant dextrin } \\
\text { group }(n 30)\end{array}$} \\
\hline & & Mean & SD & Mean & SD \\
\hline \multirow[t]{2}{*}{ Weight (kg) } & Baseline & $71 \cdot 8$ & 3.5 & $76 \cdot 0$ & 11.5 \\
\hline & End & $70 \cdot 2$ & $6 \cdot 1$ & $72.9^{*} \dagger$ & $10 \cdot 3$ \\
\hline \multirow[t]{2}{*}{ BMI $\left(\mathrm{kg} / \mathrm{m}^{2}\right)$} & Baseline & $30 \cdot 8$ & $5 \cdot 2$ & 31.8 & 4.5 \\
\hline & End & 29.9 & $4 \cdot 1$ & $30.4^{*} \dagger$ & $4 \cdot 1$ \\
\hline \multirow[t]{2}{*}{ Energy (kJ/d) } & Baseline & 7551.3 & 987.0 & 7414.0 & $1324 \cdot 6$ \\
\hline & End & $6800 \cdot 3$ & $1384 \cdot 9$ & $6009 \cdot 3^{*} \dagger$ & 951.8 \\
\hline \multirow[t]{2}{*}{ Carbohydrate $(\mathrm{g} / \mathrm{d})$} & Baseline & $194 \cdot 7$ & $62 \cdot 7$ & $211 \cdot 3$ & $66 \cdot 9$ \\
\hline & End & 221.4 & $35 \cdot 3$ & $187 \cdot 6 \dagger$ & $55 \cdot 3$ \\
\hline \multirow[t]{2}{*}{ Protein $(\mathrm{g} / \mathrm{d})$} & Baseline & $51 \cdot 9$ & 12.5 & $52 \cdot 4$ & $15 \cdot 5$ \\
\hline & End & $54 \cdot 3$ & $14 \cdot 6$ & $49 \cdot 0$ & $12 \cdot 0$ \\
\hline \multirow[t]{2}{*}{ Total fat $(\mathrm{g} / \mathrm{d})$} & Baseline & $53 \cdot 2$ & $14 \cdot 5$ & $54 \cdot 7$ & $25 \cdot 9$ \\
\hline & End & $51 \cdot 8$ & 14.9 & $43.0^{*} \dagger$ & $16 \cdot 2$ \\
\hline \multirow[t]{2}{*}{ Dietary fibre $(\mathrm{g} / \mathrm{d})$} & Baseline & $11 \cdot 6$ & $3 \cdot 4$ & $13 \cdot 4$ & $4 \cdot 2$ \\
\hline & End & $14 \cdot 2$ & 3.9 & $13 \cdot 3$ & 5.4 \\
\hline
\end{tabular}

The results of the present study for the changes in body weight and BMI are similar to those reported by GuérinDeremaux et $a l^{(10,19)}$, suggesting that supplementation with NUTRIOSE ${ }^{\circledR} 06$ at a dosage of $17 \mathrm{~g} / \mathrm{d}$ for 12 weeks and dosages of 14,18 and $24 \mathrm{~g} / \mathrm{d}$ for 9 weeks decreased body weight and BMI in overweight men. In the present trial, energy intake of the intervention group significantly decreased $(7414.0$ (sD 1324.6)-6009.3 (sD 951.8) kJ). The exact mechanism(s) of weight reduction by resistant dextrin remains unclear.
It has been hypothesised that increased the levels of leptin and some gut satiety hormones, including glucagon-like peptide (GLP)-1, peptide YY and ghrelin, as well as reduction in appetite, play an important role in weight reduction ${ }^{(10,19)}$. Furthermore, it has been reported that there is a positive relationship between increased endotoxaemia and obesity ${ }^{(20)}$. Resistant dextrin may decrease body weight through the reduction in metabolic endotoxaemia. Only one study has reported the effects of NUTRIOSE ${ }^{\circledR} 06$ supplementation on

Table 3. Changes in the glycaemic status of the study patients at baseline and at the end of the trial

(Mean values and standard deviations; mean differences (MD) and $95 \%$ confidence intervals)

\begin{tabular}{|c|c|c|c|c|c|c|c|}
\hline \multirow[b]{2}{*}{ Variables } & \multirow[b]{2}{*}{ Period } & \multicolumn{2}{|c|}{$\begin{array}{l}\text { Maltodextrin } \\
\text { group }(n 25)\end{array}$} & \multicolumn{2}{|c|}{$\begin{array}{l}\text { Resistant dextrin } \\
\text { group }(n 30)\end{array}$} & \multirow{2}{*}{$\begin{array}{c}\text { MD } \\
\text { between } \\
\text { groups }\end{array}$} & \multirow[b]{2}{*}{$95 \% \mathrm{Cl}$} \\
\hline & & Mean & SD & Mean & SD & & \\
\hline \multirow{4}{*}{$\mathrm{FPG}(\mathrm{mmol} / \mathrm{l})$} & Baseline & 8.65 & 1.55 & $9 \cdot 30$ & 1.70 & 0.65 & $-0.20,1.50$ \\
\hline & End & $8 \cdot 60$ & 0.80 & 8.65 & 1.95 & $0.05 \ddagger$ & $-1 \cdot 16,1.90$ \\
\hline & MD within groups & \multicolumn{2}{|c|}{-0.05} & \multicolumn{2}{|c|}{-0.65} & & \\
\hline & $95 \% \mathrm{Cl}$ & \multicolumn{2}{|c|}{$-0.35,0.20$} & \multicolumn{2}{|c|}{$-1 \cdot 10,0.05$} & & \\
\hline \multirow[t]{4}{*}{$\mathrm{HbA1c}(\%)$} & Baseline & $8 \cdot 2$ & $1 \cdot 0$ & $7 \cdot 8$ & 0.9 & -0.2 & $-0.7,0.3$ \\
\hline & End & 8.3 & 1.0 & 7.5 & 0.8 & 0.5 & $-1 \cdot 2,0.2$ \\
\hline & MD within groups & \multirow{2}{*}{\multicolumn{2}{|c|}{$\begin{array}{c}0.1 \\
-0.1,0.4\end{array}$}} & \multirow{2}{*}{\multicolumn{2}{|c|}{$\begin{array}{c}-0.3 \\
-0.6,0.1\end{array}$}} & & \\
\hline & $95 \% \mathrm{Cl}$ & & & & & & \\
\hline \multirow[t]{4}{*}{ Fasting insulin (pmol/l) } & Baseline & $91 \cdot 32$ & $24 \cdot 30$ & $90 \cdot 97$ & 33.70 & -0.35 & $-11 \cdot 10,21 \cdot 20$ \\
\hline & End & 93.40 & $26 \cdot 70$ & $69.80^{*} \dagger$ & $27 \cdot 35$ & $-20.07 \ddagger$ & $4 \cdot 02,36 \cdot 10$ \\
\hline & MD within groups & \multirow{2}{*}{\multicolumn{2}{|c|}{$\begin{array}{c}2.08 \\
0.70,3 \cdot 20\end{array}$}} & \multirow{2}{*}{\multicolumn{2}{|c|}{$\begin{array}{c}-21 \cdot 17 \\
-28 \cdot 50,-13.54\end{array}$}} & & \\
\hline & $95 \% \mathrm{Cl}$ & & & & & & \\
\hline \multirow[t]{4}{*}{ HOMA-IR } & Baseline & $5 \cdot 15$ & 1.50 & $5 \cdot 50$ & $2 \cdot 20$ & 0.35 & $-0.40,1.70$ \\
\hline & End & $5 \cdot 20$ & 1.6 & $3.95^{\star} \dagger$ & 1.80 & $-1.34 \ddagger$ & $-2.62,-0.06$ \\
\hline & MD within groups & \multirow{2}{*}{\multicolumn{2}{|c|}{$\begin{array}{c}-0.05 \\
-0.08,0.20\end{array}$}} & \multirow{2}{*}{\multicolumn{2}{|c|}{$\begin{array}{c}-1.55 \\
-2.10,-0.90\end{array}$}} & & \\
\hline & $95 \% \mathrm{Cl}$ & & & & & & \\
\hline \multirow[t]{3}{*}{ QUICKI } & Baseline & 2.32 & 0.10 & $2 \cdot 30$ & 0.23 & -0.02 & $-0.07,0.13$ \\
\hline & End & $2 \cdot 30$ & 0.10 & $2 \cdot 15^{\star} \dagger$ & 0.22 & $0.17 \ddagger$ & $0.01,0.33$ \\
\hline & $\begin{array}{l}\text { MD within groups } \\
95 \% \mathrm{Cl}\end{array}$ & \multicolumn{2}{|c|}{$\begin{array}{c}-0.02 \\
-0.05,0.09\end{array}$} & \multicolumn{2}{|c|}{$\begin{array}{c}-0.15 \\
-0.2,-0.1\end{array}$} & & \\
\hline
\end{tabular}

FPG, fasting plasma glucose; HOMA-IR, homeostasis model assessment of insulin resistance; QUICKI, quantitative insulin sensitivity check index. ${ }^{*}$ Mean value was significantly different from that at baseline $(P<0.05$; paired Student's $t$ test).

† Mean value was significantly different from that of the maltodextrin group $(P<0.05$; ANCOVA adjusted for energy intake, weight changes and baseline values).

$\ddagger$ Adjusted for changes in energy intake, body weight and baseline values using ANCOVA 
Table 4. Changes in lipopolysaccharide, malondialdehyde (MDA) and inflammatory biomarkers of the study patients at baseline and at the end of the trial

(Mean values and standard deviations; mean differences (MD) and $95 \%$ confidence intervals)

\begin{tabular}{|c|c|c|c|c|c|c|c|}
\hline \multirow{2}{*}{$\frac{\text { Variables }}{\text { hs-CRP } \ddagger(\mathrm{ng} / \mathrm{ml})}$} & \multirow{2}{*}{$\begin{array}{l}\text { Period } \\
\text { Baseline }\end{array}$} & \multicolumn{2}{|c|}{$\begin{array}{l}\text { Maltodextrin } \\
\text { group }(n 25)\end{array}$} & \multicolumn{2}{|c|}{$\begin{array}{l}\text { Resistant dextrin } \\
\text { group }(n 30)\end{array}$} & \multirow{3}{*}{$\begin{array}{c}\begin{array}{c}\text { MD between } \\
\text { groups }\end{array} \\
-3 \cdot 10 \\
-2.69 \S\end{array}$} & \multirow{3}{*}{$\begin{array}{r}95 \% \mathrm{Cl} \\
-7 \cdot 15,0.93\end{array}$} \\
\hline & & $12 \cdot 50$ & $7 \cdot 40$ & $9 \cdot 40$ & 3.95 & & \\
\hline & End & \multirow{2}{*}{\multicolumn{2}{|c|}{0.30}} & $7 \cdot 00^{\star}$ & 4.90 & & \\
\hline & MD within groups & & & \multicolumn{2}{|c|}{-2.40} & & \\
\hline & $95 \% \mathrm{Cl}$ & \multicolumn{2}{|c|}{$-0.03,1.05$} & \multicolumn{2}{|c|}{$-3.35,-1.40$} & & \\
\hline \multirow{4}{*}{ TNF- $\alpha(p g / m l)$} & Baseline & 17.40 & 3.94 & $17 \cdot 30$ & $4 \cdot 20$ & -0.10 & $-2 \cdot 60,2 \cdot 40$ \\
\hline & End & 18.02 & 3.9 & $15 \cdot 00^{*} \dagger$ & 4.95 & $-5.40 \S$ & $-7.89,-2.91$ \\
\hline & MD within groups & \multicolumn{2}{|c|}{0.62} & \multicolumn{2}{|c|}{$-2 \cdot 30$} & & \\
\hline & $95 \% \mathrm{Cl}$ & \multicolumn{2}{|c|}{$-0.25,1.50$} & \multicolumn{2}{|c|}{$-3 \cdot 30,-1.40$} & & \\
\hline \multirow[t]{4}{*}{ IL-6 (pg/ml) } & Baseline & 5.90 & $2 \cdot 15$ & $6 \cdot 45$ & $2 \cdot 15$ & 0.55 & $-0.95,2.05$ \\
\hline & End & $6 \cdot 20$ & 1.60 & $5 \cdot 05^{*} \dagger$ & 3.5 & $-1.45 \S$ & $-2.61,-0.28$ \\
\hline & MD within groups & \multicolumn{2}{|c|}{0.30} & \multicolumn{2}{|c|}{-1.40} & & \\
\hline & $95 \% \mathrm{Cl}$ & \multicolumn{2}{|c|}{$-0.20,0.80$} & \multicolumn{2}{|c|}{$-1.90,-0.90$} & & \\
\hline \multirow{4}{*}{ MDA (nmol/ml) } & Baseline & 3.85 & 1.22 & $4 \cdot 30$ & 1.92 & 0.55 & $-0.5,1.5$ \\
\hline & End & 4.30 & 1.88 & $3 \cdot 20^{*} \dagger$ & 1.31 & $-1 \cdot 21 \S$ & $-2.42,-0.40$ \\
\hline & MD within groups & \multicolumn{2}{|c|}{0.55} & \multicolumn{2}{|c|}{$-1 \cdot 10$} & & \\
\hline & $95 \% \mathrm{Cl}$ & \multicolumn{2}{|c|}{$-0.12,1.20$} & \multicolumn{2}{|c|}{$-1.50,-0.61$} & & \\
\hline \multirow[t]{3}{*}{ Endotoxin (EU/ml) } & Baseline & $25 \cdot 4$ & $5 \cdot 7$ & $25 \cdot 3$ & $6 \cdot 3$ & -0.1 & $-3.9,3 \cdot 6$ \\
\hline & End & $25 \cdot 6$ & $6 \cdot 2$ & $20 \cdot 9^{*} \dagger$ & $6 \cdot 5$ & $-6 \cdot 1 \S$ & $-10 \cdot 1,-2 \cdot 1$ \\
\hline & $\begin{array}{l}\text { MD within groups } \\
95 \% \mathrm{Cl}\end{array}$ & \multicolumn{2}{|c|}{$\begin{array}{c}0.2 \\
-1.0,1.3\end{array}$} & \multicolumn{2}{|c|}{$\begin{array}{c}-4.4 \\
-6 \cdot 0,-3.0\end{array}$} & & \\
\hline
\end{tabular}

hs-CRP, high-sensitivity C-reactive protein; EU, endotoxin units.

* Mean value was significantly different from that at baseline $(P<0.05$; paired Student's $t$ test).

† Mean value was significantly different from that of the maltodextrin group $(P<0.05$; ANCOVA adjusted for energy intake, weight changes and baselines values).

† hs-CRP analyses were performed after log transformation.

$\S$ Adjusted for changes in energy intake, body weight and baseline values using ANCOVA.

glycaemic status in overweight men. It has shown that NUTRIOSE ${ }^{\circledR} 06$ reduces the levels of glucose (4\%), insulin $(12 \%)$ and HOMA-IR (18\%) in overweight men ${ }^{(9)}$. Regarding insulin and HOMA-IR, the present results are consistent with the findings of that study. We observed non-significant reductions in the levels of FPG and HbA1c. The discrepancy in the results for FPG and HbA1c may be due to study duration and dosage of the supplement. The results obtained for the effects of other prebiotics on glycaemic status in diabetic patients are inconsistent. We have reported the positive effects of inulintype fructans, as a prebiotic, on glycaemic status in diabetic patients ${ }^{(17,18)}$. By contrast, another study has reported no effects of inulin-type fructans in diabetic patients ${ }^{(21)}$. This difference in results may be attributed to the basal levels of glycaemic indices, the dosage and type of supplementation, as well as the pathological state of patients. Prebiotics such as resistant dextrin may promote hypoglycaemic effects via several mechanisms discussed below.

\section{Modification in gut hormone secretion}

Supplementation with prebiotics has been reported to promote L-cell differentiation in the colon and increase the secretion of gut hormones including peptide YY, GLP-1 and gastric inhibitory polypeptide ${ }^{(22)}$. Prebiotics probably modulate these effects through an increase in the bacterial production of butyrate and propionate that activates G-protein-coupled receptors, free fatty acid receptor 2 and free fatty acid receptor $3^{(23)}$. These hormones contribute to the regulation of appetite and control of glucose metabolism and insulin resistance, respectively. By these mechanisms, resistant dextrin, as a prebiotic, may control glycaemic and insulinaemic responses.

\section{Reduction in body weight}

Excess body weight can affect the expression of inflammatory biomarkers such as TNF- $\alpha$, which reinforce insulin resistance via suppressing insulin intracellular signals such as inhibitory phosphorylation of insulin receptor substrates (IRS-1 and IRS-2) ${ }^{(24)}$. Resistant dextrin is likely to decrease hyperglycaemia by increasing anorexigenic hormone levels, decreasing body weight as well as BMI, and subsequently reducing inflammation $^{(19)}$.

\section{Improvement in metabolic endotoxaemia}

Endotoxin levels are higher (76\%) in individuals with type 2 diabetes than in healthy individuals ${ }^{(25)}$. Increased endotoxin levels (metabolic endotoxaemia) cause disturbance in food intake and energy expenditure control, which may favour weight gain ${ }^{(20)}$ and consequently develop insulin resistance. Moreover, metabolic endotoxaemia causes an increase in the expression of pro-inflammatory cytokines such as IL-1, IL-6 and TNF- $\alpha^{(26)}$. The increase in the levels of these proinflammatory cytokines is related to the decrease in insulin action via molecular mechanisms such as inhibitory phosphorylation of IRS- 1 and IRS-2 by activating c-Jun $\mathrm{NH}_{2}-$ terminal kinase and $\mathrm{I} \kappa \mathrm{B}$ kinase, reducing the expression of IRS-1 and IRS-2 via p38 mitogen-activated protein kinase, 
and suppressing the expression of IRS-1 and IRS-2 via the extracellular signal-related kinase pathway ${ }^{(27)}$. Resistant dextrin may contribute to the modulation of glycaemic status by reducing body weight and inflammatory biomarkers through decreased metabolic endotoxaemia.

\section{Modulation of butyrate and NEFA levels}

In diabetic patients, a reduction in insulin anti-lipolytic activity helps to increase NEFA levels, leading to cellular dysfunction of insulin in several tissues by decreasing IRS-1-associated phosphatidylinositol 3-kinase activity and consequently insulin resistance. Animal studies have indicated that butyrate, as a SCFA, reverses diet-induced insulin resistance, possibly by enhancing the expression of PPAR- $\gamma$ that increases fatty acid oxidation in muscles ${ }^{(28)}$. Butyrate reduces gut permeability by increasing the release of GLP-2, which, in turn, helps to reduce the level of serum endotoxin ${ }^{(29)}$ that is known to induce inflammation and subsequently resistant insulin ${ }^{(26,27)}$. Moreover, GLP-2 improves glucose homeostasis and insulin sensitivity by activating phosphatidylinositol 3-kinase signalling ${ }^{(30)}$. NUTRIOSE ${ }^{\circledR} 06$, as a butyrogenic prebiotic, may modulate glycaemic status by the aforementioned mechanisms.

Another outcome of resistant dextrin supplementation was to improve inflammatory biomarkers, i.e. MDA and metabolic endotoxaemia. To the best of our knowledge, no previous study has evaluated the effects of resistant dextrin on the mentioned biomarkers in human subjects. In colitis piglets, supplementation with NUTRIOSE ${ }^{\circledR} 06$, as a resistant dextrin, decreased systemic concentrations of IL-1 $\beta$, IL-12 as well as TNF- $\alpha$ and stimulated the $\mathrm{T}$ helper (Th)2-related immune pathway (IL-10 and secretory $\operatorname{IgA})^{(7)}$. In $o b / o b$ mice, supplementation with oligofructose led to decreases in the levels of cytokines, such as TNF- $\alpha$, IL-1 $\beta$, IL-1, IL- 6 and interferon- $\gamma$, and the hepatic expression of inflammatory and oxidative stress markers ${ }^{(29)}$. Some human studies have reported the positive effects of other prebiotics on inflammatory biomarkers ${ }^{(31-33)}$. In patients with non-alcoholic steatohepatitis, it has been shown that supplementation with Bifidobacterium longum plus fructo-oligosaccharides significantly reduces the levels of TNF- $\alpha$, C-reactive protein, HOMA-IR, serum endotoxins and steatosis ${ }^{(31)}$. Research has shown that supplementation with inulin and xylo-oligosaccharide $(3 \mathrm{~g}$ inulin $+1 \mathrm{~g}$ xylo-oligosaccharide) for 4 weeks significantly decreases the expression of IL- $1 \beta$ and TNF- $\alpha$ and increases the expression of IL-13 and IL-10 in the blood of healthy volunteers ${ }^{(32)}$. It has been reported that supplementation of trans-galacto-oligosaccharide $(5.5 \mathrm{~g} / \mathrm{d})$, as a prebiotic, for 12 weeks improves IgA, insulin, lipid and C-reactive protein status in overweight adults ${ }^{(33)}$. Moreover, it has previously been reported that inulin-type fructans, as a prebiotic, improve glycaemic indices, oxidative stress ${ }^{(17)}$, some inflammatory biomarkers and metabolic endotoxaemia in women with type 2 diabetes $^{(18,34)}$.

In contrast, Macfarlane et al. ${ }^{(35)}$ reported that supplementation of older people with a synbiotic (B. longum + Synergy 1) for 4 weeks significantly decreases the level of TNF- $\alpha$. They observed a non-significant reduction in the levels of interferon- $\gamma$, IL-4, IL-6, IL-8, monocyte chemoattractant protein-1 and IL-1 as well as a non-significant increase in the level of IL-10. Anderson et al. ${ }^{(36)}$ found that supplementation with oligofructose plus probiotics (for 1-2 weeks in patients undergoing elective abdominal surgery) did not affect systemic inflammation. The diversity of these results may be due to the differences in ethnicity, genotype, study duration, dosage, type and time of supplementation, pathological state, as well as basal status of inflammatory/antiinflammatory status of patients.

The underlying mechanism(s) of resistant dextrin affecting inflammation are not yet known. Some probable proposed mechanism(s) are presented below.

Shift in the gut ecosystem. NUTRIOSE ${ }^{\circledR} 06$, as a resistant dextrin, has been reported to shift the bacterial microbiota profile to butyrogenic genera such as Peptostreptococcus, Fusobacterium and Bifidobacterium ${ }^{(37)}$. Probiotics of the Bifidobacterium genus are well known for their antiinflammatory activities ${ }^{(38)}$. Moreover, human studies have shown that NUTRIOSE ${ }^{\circledR} 06$ changes the bacterial microbiota profile towards Lactobacillus spp. ${ }^{(39)}$. It has been shown that the Lactobacillus genus down-regulates IL-12 and TNF- $\alpha$, enhances IL-10 in dendritic cells, and controls the regulation of dendritic cell functions, resulting in their inability to induce $\mathrm{CD}^{+}{ }^{+} \mathrm{T}$-cell activation ${ }^{(40)}$

SCFA from resistant dextrin fermentation in the colon. Clinical trials on healthy subjects have shown that resistant dextrin stimulates the growth of acid-resistant bacteria ${ }^{(37)}$. These bacterial genera are well known to produce butyrate $^{(41)}$. Butyrate controls inflammation by preventing inhibitor of $\kappa \beta$ degradation and the production of $N F-\kappa \beta^{(42)}$ and by increasing the expression of cytokine signalling 3 suppressor ${ }^{(43)}$. These changes shift lymphocyte differentiation into Th2 rather than Th1 cells, thereby increasing the secretion of IL-10 and decreasing the expression of pyrogenic factors, such as myeloperoxidase ${ }^{(8)}$. Th2 inhibits the production of inflammatory cytokines by interfering with the Tolllike receptor 4-dependent signalling pathway by activating PPAR- $\gamma^{(44)}$. PPAR- $\gamma$ exerts its anti-inflammatory effect by directly binding to as well as modulating the expression and activity of the peptidoglycan recognition protein 3 (PGlyRP3) gene, which, in turn, activates inhibitor of $\kappa \beta$ and inhibits NF- $\kappa \beta$ translocation into the nucleus, resulting in the down-regulation of different pro-inflammatory cytokines ${ }^{(45)}$.

Reduction of oxidative stress by increasing Lactobacillus and decreasing hyperglycaemia and NEFA levels. Increased oxidative stress results in an increase in intestinal permeability and the levels of endotoxin in the blood. Lipopolysaccharide is a major component of the outer cell wall in Gram-negative bacteria, and is known as an inflammatory agent in obesity and type 2 diabetes $^{(29)}$. Lactic acid bacteria produce superoxide dismutase. An in vitro study has shown that antioxidant properties of lactic acid bacteria leads to the elimination of free radicals ${ }^{(46)}$. Also, Lactobacillus spp. resident in gut lyses release their intracellular antioxidative constituents, which, in turn, help to decrease the level of $\mathrm{MDA}^{(46)}$. Moreover, it has been reported that NUTRIOSE ${ }^{\circledR} 06$ can increase $\beta$-glucosidase activity that is known for its antioxidative effects ${ }^{(37)}$. 


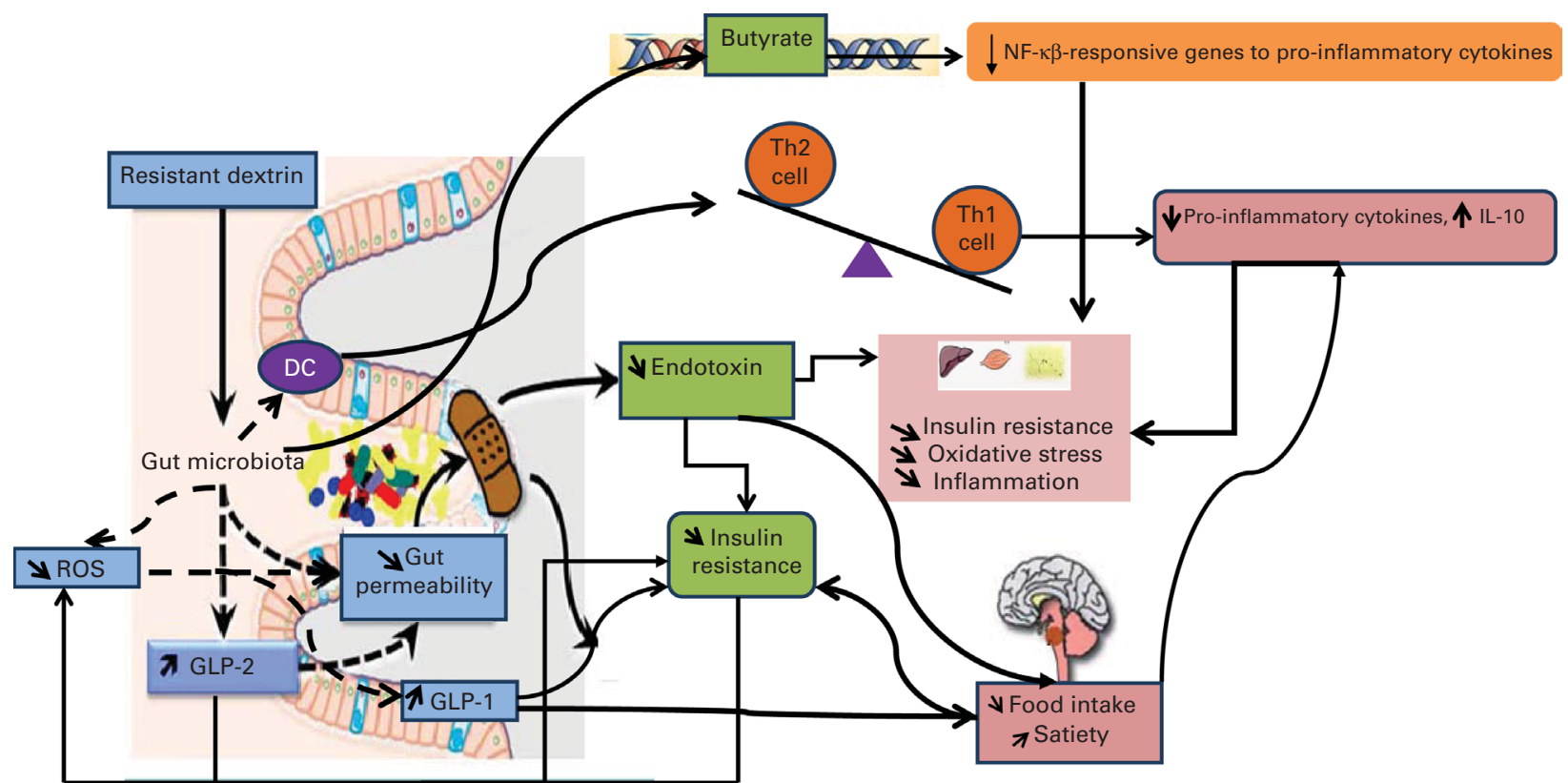

Fig. 2. Probable mechanisms of the effect of resistant dextrin on inflammation and insulin resistance. Th, T helper; DC, dendritic cells; ROS, reactive oxygen species; GLP, glucagon-like peptide. A colour version of this figure can be found online at http://www.journals.cambridge.org/bjn

Hyperglycaemia and probably increased levels of NEFA induce high concentrations of reactive oxygen species $^{(47)}$. We have found that resistant dextrin improves the lipid profile (P Dehghan et al., unpublished results).

Reduction of serum endotoxin levels. Resistant dextrin, as a prebiotic, may reduce the tone of inflammation via the reduction of intestinal permeability due to increased GLP-2 and normalisation of the Gram-negative:Gram-positive ratio that leads to the reduction of endotoxin levels (endotoxaemia $)^{(29)}$. The probable mechanisms are shown in Fig. 2.

The present trial had some limitations, including its sample size, fairly short duration of its intervention, as well as no assessment of serum SCFA and NEFA levels among other inflammatory and anti-inflammatory biomarkers. Additionally, gut and faecal microbial compositions were not evaluated in the present study. Based on the results of the present trial, it can be hypothesised that resistant dextrin supplementation may improve insulin resistance and some of the oxidative stress and inflammatory biomarkers in type 2 diabetic patients. These findings suggest resistant dextrin to be a safe intervention for the management of type 2 diabetes and its complications. This dietary fibre can be considered as a supplement in the food industry, especially as a substitute for sugar and fat in foods for diabetic patients. Further investigations are needed to confirm the positive effects of resistant dextrin on insulin resistance and inflammatory/ anti-inflammatory indices in type 2 diabetic patients.

\section{Acknowledgements}

The authors thank all the patients who participated in the study.

The present study was financially supported by the Nutrition Research Center of Tabriz University of Medical Sciences,
Iran. The study received no specific grant from commercial or not-for-profit sectors. The Nutrition Research Center of Tabriz University of Medical Sciences had no role in the design and analysis of the study or in the writing of this article.

The authors' contributions are as follows: P. D., M. A. J.-A. and B. P. G. designed the study; P. D. and A. A. conducted the trial and collected the data; P. D. and M. A. J.-A. analysed the data; A. A., B. P. G. and P. D. wrote and revised the final manuscript.

The authors declare that there are no conflicts of interest.

\section{References}

1. Lotfi MH, Saadati H \& Afzali M (2014) Prevalence of diabetes in people aged $\geq 30$ years: the results of screening program of Yazd province, Iran, in 2012. J Res Health Sci 14, 87-91.

2. Goldberg RB (2009) Cytokine and cytokine-like inflammation markers, endothelial dysfunction, and imbalanced coagulation in development of diabetes and its complications. J Clin Endocrinol Metab 94, 3171-3182.

3. Zhang Y \& Zhang H (2013) Microbiota associated with type 2 diabetes and its related complications. Food Sci Hum Wellness 2, 167-172.

4. Kaczmarczyk MM, Miller MJ \& Freund GG (2012) The health benefits of dietary fiber: beyond the usual suspects of type 2 diabetes mellitus, cardiovascular disease and colon cancer. Metabolism 61, 1058-1066.

5. Lefranc-Millot C (2008) NUTRIOSE ${ }^{\circledR}$ 06: a useful soluble dietary fibre for added nutritional value. Nutr Bull 33, 234-239.

6. Hobden MR, Martin-Morales A, Guérin-Deremaux L, et al. (2013) In vitro fermentation of NUTRIOSE ${ }^{\circledR}$ FB06, a wheat dextrin soluble fibre, in a continuous culture human colonic model system. PLOS ONE 8, e77128.

7. Pouillart PR, Depeint F, Abdelnour A, et al. (2010) Nutriose, a prebiotic low-digestible carbohydrate, stimulates gut mucosal immunity and prevents TNBS-induced colitis in piglets. Inflamm Bowel Dis 16, 783-794. 
8. Knapp BK, Parsons CM, Bauer LL, et al. (2010) Soluble fiber dextrins and pullulans vary in extent of hydrolytic digestion in vitro and in energy value and attenuate glycemic and insulinemic responses in dogs. J Agric Food Chem 58, $11355-11363$.

9. Li S, Guérin-Deremaux L, Pochat M, et al. (2010) NUTRIOSE dietary fiber supplementation improves insulin resistance and determinants of metabolic syndrome in overweight men: a double-blind, randomized, placebo-controlled study. Appl Physiol Nutr Metab 35, 773-782.

10. Guérin-Deremaux L, Pochat M, Reifer C, et al. (2013) Dose-response impact of a soluble fiber, NUTRIOSE ${ }^{\circledR}$, on energy intake, body weight and body fat in humans. Global Epidemic Obesity 1, 1-8.

11. American Diabetes Association (2004) Diagnosis and classification of diabetes mellitus. Diabetes Care 27, Suppl. 1, S5-S10.

12. Saghaei M (2004) Random allocation software for parallel group randomized trials. BMC Med Res Methodol 4, 26.

13. Pocock SJ (1990) Clinical Trials - A Practical Approach, pp. 128. Chichester: John Wiley \& Sons.

14. Matthews DR, Hosker JP, Rudenski AS, et al. (1985) Homeostasis model assessment: insulin resistance and $\beta$-cell function from fasting plasma glucose and insulin concentrations in man. Diabetologia 28, 412-419.

15. Katz A, Nambi SS, Mather K, et al. (2000) Quantitative insulin sensitivity check index: a simple, accurate method for assessing insulin sensitivity in humans. J Clin Endocrinol Metab 85, 2402-2410.

16. Del Rio D, Pellegrini N, Colombi B, et al. (2003) Rapid fluorimetric method to detect total plasma malondialdehyde with mild derivatization conditions. Clin Chem 49, 690-692.

17. Pourghassem Gargari B, Dehghan P, Aliasgharzadeh A, et al. (2013) Effects of high performance inulin supplementation on glycemic control and antioxidant status in women with type 2 diabetes. Diabetes Metab J 37, 140-148.

18. Dehghan P, Pourghassem Gargari B \& Asghari Jafar-Abadi M (2014) Oligofructose-enriched inulin improves some inflammatory markers and metabolic endotoxemia in women with type 2 diabetes mellitus: a randomized controlled clinical trial. Nutrition 30, 418-423.

19. Guérin-Deremaux L, Li S, Pochat M, et al. (2011) Effects of NUTRIOSE ${ }^{\circledR}$ dietary fiber supplementation on body weight, body composition, energy intake, and hunger in overweight men. Int J Food Sci Nutr 62, 628-635.

20. Amar J, Burcelin R, Ruidavets JB, et al. (2008) Energy intake is associated with endotoxemia in apparently healthy men. Am J Clin Nutr 87, 1219-1223.

21. Bonsu Nana KA \& Johnson Shanthi (2012) Effects of inulin fibre supplementation on serum glucose and lipid concentration in patients with type 2 diabetes. Int $J$ Diabetes Metab 21, 80-86.

22. Cani PD, Lecourt E, Dewulf EM, et al. (2009) Gut microbiota fermentation of prebiotics increases satietogenic and incretin gut peptide production with consequences for appetite sensation and glucose response after a meal. Am J Clin Nutr 90, 1236-1243.

23. Lin HV, Frassetto A, Kowalik EJ Jr, et al. (2012) Butyrate and propionate protect against diet-induced obesity and regulate gut hormones via free fatty acid receptor 3-independent mechanisms. PLOS ONE 7, e35240.

24. Kueht ML, McFarlin BK \& Lee RE (2009) Severely obese have greater LPS-stimulated TNF- $\alpha$ production than normal weight African-American women. Obesity 17, 447-451.

25. Creely SJ, McTernan PG, Kusminski CM, et al. (2007) Lipopolysaccharide activates an innate immune system response in human adipose tissue in obesity and type 2 diabetes. $A m J$ Physiol Endocrinol Metab 292, E740-E747.

26. Cani PD \& Delzenne NM (2011) The gut microbiome as therapeutic target. Pharmacol Ther 130, 202-212.

27. Fujishiro M, Gotoh Y, Katagiri H, et al. (2003) Three mitogenactivated protein kinases inhibit insulin signaling by different mechanisms in 3T3-L1 adipocytes. Mol Endocrinol 17, 487-497.

28. Gao Z, Yin J, Zhang J, et al. (2009) Butyrate improves insulin sensitivity and increases energy expenditure in mice. Diabetes 58, 1509-1517.

29. Cani PD, Possemiers S, Van de Wiele T, et al. (2009) Changes in gut microbiota control inflammation in obese mice through a mechanism involving GLP-2-driven improvement of gut permeability. Gut 58, 1091-1103.

30. Shi X, Zhou F, Li X, et al. (2013) Central GLP-2 enhances hepatic insulin sensitivity via activating PI3K signaling in POMC neurons. Cell Metab 18, 86-98.

31. Malaguarnera M, Vacante M, Antic T, et al. (2012) Bifidobacterium longum with fructo-oligosaccharides in patients with non alcoholic steatohepatitis. Dig Dis Sci 57, 545-553.

32. Lecerf JM, Depeint F, Clerc E, et al. (2012) Xylo-oligosaccharide (XOS) in combination with inulin modulates both the intestinal environment and immune status in healthy subjects, while XOS alone only shows prebiotic properties. Br J Nutr 108, 1847-1858.

33. Vulevic J, Juric A, Tzortzis G, et al. (2013) A mixture of trans-galactooligosaccharides reduces markers of metabolic syndrome and modulates the fecal microbiota and immune function of overweight adults. J Nutr 143, 324-331.

34. Dehghan P, Gargari BP, Jafar-Abadi MA, et al. (2014) Inulin controls inflammation and metabolic endotoxemia in women with type 2 diabetes mellitus: a randomizedcontrolled clinical trial. Int J Food Sci Nutr 65, 117-123.

35. Macfarlane S, Cleary S, Bahrami B, et al. (2013) Synbiotic consumption changes the metabolism and composition of the gut microbiota in older people and modifies inflammatory processes: a randomised, double-blind, placebocontrolled crossover study. Aliment Pharmacol Ther 38, $804-816$

36. Anderson AD, McNaught CE, Jain PK, et al. (2004) Randomised clinical trial of synbiotic therapy in elective surgical patients. Gut 53, 241-245.

37. van den Heuvel EG, Wils D, Pasman WJ, et al. (2005) Dietary supplementation of different doses of NUTRIOSE FB, a fermentable dextrin, alters the activity of faecal enzymes in healthy men. Eur J Nutr 44, 445-451.

38. Suzuki A, Mitsuyama K, Koga H, et al. (2006) Bifidogenic growth stimulator for the treatment of active ulcerative colitis: a pilot study. Nutrition 22, 76-81.

39. Lefranc-Millot C, Wils D, Neut C, et al. (2006) Effects of a soluble fibre with excellent tolerance, NUTRIOSE ${ }^{\circledR} 06$, on the gut ecosystem: a review. In Proceedings of The Dietary Fibre Conference 2006, p. 34, Helsinki, Finland.

40. Mohamadzadeh M, Pfeiler EA, Brown JB, et al. (2011) Regulation of induced colonic inflammation by Lactobacillus acidophilus deficient in lipoteichoic acid. Proc Natl Acad Sci U S A 108, 4623-4630.

41. Lefranc-Millot C, Wils D, Henry J, et al. (2006) NUTRIOSE ${ }^{\circledR}$, a resistant dextrin, and MALTISORB ${ }^{\circledR}$, a sugar alcohol, two key ingredients for healthy diets and obesity management. Obes Rev 7, S269.

42. Place RF, Noonan EJ \& Giardina C (2005) HDAC inhibition prevents NF- $\mathrm{BB}$ activation by suppressing proteasome activity: down-regulation of proteasome subunit expression stabilizes IкB $\alpha$. Biochem Pharmacol 70, 394-406. 
43. Weber TE \& Kerr BJ (2006) Butyrate differentially regulates cytokines and proliferation in porcine peripheral blood mononuclear cells. Vet Immunol Immunopathol 113, 139-147.

44. Schwab M, Reynders V, Loitsch S, et al. (2007) Involvement of different nuclear hormone receptors in butyrate-mediated inhibition of inducible NF- $\mathrm{BB}$ signaling. Mol Immunol 44, 3625-3632.

45. Zenhom M, Hyder A, de Vrese M, et al. (2011) Prebiotic oligosaccharides reduce proinflammatory cytokines in intestinal Caco-2 cells via activation of PPAR $\gamma$ and peptidoglycan recognition protein 3. J Nutr 141, 971-977.

46. Rishi P, Mavi SK, Bharrhan S, et al. (2009) Protective efficacy of probiotic alone or in conjunction with a prebiotic in Salmonella-induced liver damage. FEMS Microbiol Ecol 69, 222-230.

47. King GL \& Loeken MR (2004) Hyperglycemia-induced oxidative stress in diabetic complications. Histochem Cell Biol 122, 333-338. 